\title{
Publication Review
}

\section{Animals, Welfare and the Law: Fundamental Principles for Critical Assessment}

Earthscan from Routledge: London and New York, 2015, i-xi + 288 pages.

ISBN: 978-0-415-53562-5 (hardback, £90.00); 978-0-415-53563-2 (paperback, £29.99);

\section{8-0-203-11231-1 (e-book)}

Ian A. Robertson

Reviewed by Diane Ryland

Subject: Animal Welfare

'Animals, Welfare and the Law' fills a vacuum. Ian Robertson should be commended for the characteristic way in which the book is written and structured and for its substantive content. This text, based on twenty nine fundamental principles underlying the human/animal relationship, certainly makes the reader take stock and think at the outset. But the author invites his reader to do more: to use these principles, not only as aids to learning but, more importantly, to assess critically, the current state of the law in order to drive the development of animal welfare law. In this way, his 'objectivity' is not set in stone in acknowledging the legality of the status quo, i.e. that the law exists with one primordial legal formula, namely, the prevention of unnecessary and/or unreasonable pain or distress of an animal. The central theme is that 'this is the sole and continued interest of the animal and its experience that is protected by law.'

Drawing on the guiding international and intergovernmental animal welfare principles of the World Organisation for Animal Health's (OIE) Terrestrial Animal Health Code, ${ }^{1}$ the author incisively emphasises the fact that 'animal welfare is a multifactorial international and domestic public policy subject, incorporating scientific, ethical and economic issues as well as religious, cultural and trade considerations'(A further link in the chain of principles holds that 'the law has a responsibility to balance and prioritise the interest of all stakeholders, where animals and humans are each one, but not the only stakeholder.' Furthermore, and inter alia, '[e]mpirical evidence (i.e. science) is a key informant of the law, and is commonly used as a basis for providing credibility to national and international standard setting.'

The author's background as a legal practitioner - a Barrister and Solicitor of the High Court of New Zealand, and as a qualified veterinary professional, is evidently conveyed in the book's nine chapters. In the introduction, the reader is motivated to critically assess how the law balances and prioritises the interests and conflicts of key stakeholders attached to the uses of animals in human society with reference to the foundational principles described in the book, which is divided into three parts. Part I, 'Animal welfare and the need for a critical perspective', considers in chapter 2 what is so important about animal welfare and the law,

\footnotetext{
12015 COIE (Office International des Épizooties), http://www.oie.int/index.php?id=169\&L=0\&htmfile=titre1.7.htm
} 
emphasising in chapter 3 the need for critical assessment rather than emotional reaction. Tools facilitative of critical appraisal are provided with which the reader is instructed to engage, utilising three key concepts, namely objectivity, authority, and practicality. The foundational principles underpinning animal welfare law are fleshed out in Part II, with 'Religion and reaction: the foundations of animal welfare law' being the subject of chapter 4 . 'National law: the public's voice of what is acceptable' follows in chapter 5, with chapter 6 entitled "International law is international 'persuasion'." A critical and appropriate assessment of the 'controversial' use of animals in research and in food production in agriculture and the application of the fundamental principles of animal welfare and the law, constitute the respective content of chapters 7 and 8, in Part III - 'Putting the principles and law into practice'. Chapter 9 is aptly titled 'Animal welfare law: the continuing journey'.

This book has something for everyone: A historical perspective; religion; ethics; science; animals as property; criminal law in practice; European Union law and, arguably, sentience; civil law; veterinary responsibilities; international animal welfare principles; international trade law; and case studies. There is some repetition in the practical application of the principles, serving to reinforce the learning process of the reader, with some concentration on practitioners' law. The reviewer would have liked more analysis of the Animal Welfare (England and Wales) Act 2006, although accepts the book's focus on the law of New Zealand and Australia.

It can be argued that where the law stops, animal welfare need not do so. Animal welfare standards deserve to evolve in an era of rising food demand and intensive farming practices, if only to raise standards of animal welfare for human gain. The minimum standards of the law and the lowest common denominator standards attained by consensus/majority vote are not currently all encompassing and do not provide the comprehensive 'floor' that the law, arguably, has a responsibility to provide. The Organisation for Economic Cooperation and Development would appear to recognise the fact that the provision of animal welfare enhanced agri-produce is a public good, ${ }^{2}$ which serves to reinforce the responsibility of public bodies in this regard. The current state of the law can be challenged using Ian Robertson's very wise assertion, i.e. that 'objective, authoritative and practical assessment requires informed and balanced consideration of the range of conflicting and competing substantive opinions attached to the subject of animals and their welfare, in order to understand and appropriately prioritise the interests of animals as one of many stakeholders associated with matters of animal welfare.'

In an increasingly global market for agri-food produce, the question as to 'whether the law, and the courts, are the appropriate instruments by which to strike the balance between the respective interests ${ }^{3}$ may be answered in the negative. That the public authorities should provide the floor of animal welfare standards on which initiatives such as voluntary schemes

\footnotetext{
${ }^{2}$ Organisation for Economic Co-operation and Development (OECD), Multifunctionality: Towards an Analytical Framework (Paris, 2001) at 13.

${ }^{3}$ p. 32, n. 1, citing M.S.R. Palmer, 'A Perspective on Balance and the Role of Law' in D. Carter and M.Palmer (eds) Roles \& Perspectives in the Law: Essays in Honour of Sir Ivor Richardson (Victoria University Press, 2002).
} 
may be based should be the basic premise. Then, albeit requiring further qualification let the market decide, a market in which science may not be the overriding factor influencing consumers' ethical choice in the food chain. Some hybridity in standards of animal welfare is already evident; Ian Robertson does advert to the evolving private animal welfare standards of retailers and industry. But reference to 'better practice,' and to the 'best practice' promoted by international non-governmental organisations, in an 'objective assessment' of informed opinion deserves greater scrutiny with a view to greater recognition, beyond that paid to an assessment of the law in the global food chain. The book's author holds the view that nongovernmental organisations (NGO's) specialising in animal welfare are advocates of 'best practice', whereas retailers standards of 'better practice' seem more attainable. Based on authority and objectively, the NGO's standards may well be the ones that the informed consumer holds out for and uses to press for incremental change in the law, in the interim serving to raise standards of animal welfare in the marketplace/the food chain for human gain. Credit is due to the author for his hypotheses in this regard.

The book's balanced approach (for the most part) is reinforced in its concluding comments, which project as follows: '[O]n its journey of development, perhaps animal welfare and law has reached the end of its beginning now that the public, politicians, legislators and wider governing bodies recognise that the subject of animal welfare goes well beyond the altruistic moral views of a minority, and constitutes what has been described as a complex international public policy issue with important scientific, ethical, cultural, religious and trade policy implications.'

Overall, this book is an essential resource for the burgeoning number of students and researchers in the evolving interdisciplinary study of animal welfare, standards of protection, and the law. This excellent work provides the much needed springboard of fundamental principles of animal welfare and the law for further critical analysis. It is hoped that it will provoke the many varied, representative stakeholders interested in animal welfare, including the academic, into driving up standards of animal welfare. 